\title{
Undifferentiated Carcinoma of the Uterine Cervix with Evidence of Its Origin from Small-Cell Neuroendocrine Carcinoma
}

\begin{abstract}
Neuroendocrine carcinoma (NEC) of the uterine cervix is an uncommon aggressive tumor, comprises $<5 \%$ of the cervical malignancies. Undifferentiated carcinoma of the cervix, described by the World Health Organization Classification of Tumors as a distinct entity, is extremely rare with no histologic evidence of differentiation. Immunohistochemistry with p63 and neuroendocrine markers helps in delineating the type as undifferentiated squamous cell carcinoma or NEC. NEC of the uterine cervix behaves biologically like any other cervical malignancy, has an association with human papillomavirus, and is similar to NEC of any possible site with early metastasis and poorer survival. We present a case of 45 -year-old premenopausal female with undifferentiated carcinoma of the uterine cervix originating from small-cell NEC proven by the presence of differentiated component in the proximity of undifferentiated tumor and by the immunohistochemistry.
\end{abstract}

Keywords: Human papillomavirus, neuroendocrine carcinoma, undifferentiated carcinoma, uterine cervix

\section{Introduction}

Neuroendocrine carcinoma (NEC) of the uterine cervix is an uncommon tumor, accounting $<5 \%$ of the cervical malignancies. Small-cell NEC (SCNEC) is the predominant type, with early spread of disease and poorer survival, in spite of multimodal therapies..$^{[1,2]}$ Undifferentiated carcinoma of the uterine cervix is extremely rare with no obvious histologic evidence of differentiation. It can be typed as undifferentiated squamous cell carcinoma or NEC by immunohistochemistry using p63 and panel of neuroendocrine markers. We report an extremely rare case of undifferentiated carcinoma of the uterine cervix, originating from SCNEC, proven by immunohistochemistry and the presence of differentiated NEC component in the proximity.

\section{Case Report}

A premenopausal, P2 L2 female, presented with complaints of bleeding per vagina for 3 months and cervix biopsy report of moderately differentiated squamous cell carcinoma. She underwent right hemithyroidectomy for benign thyroid

This is an open access journal, and articles are distributed under the terms of the Creative Commons Attribution-NonCommercial-ShareAlike 4.0 License, which allows others to remix, tweak, and build upon the work non-commercially, as long as appropriate credit is given and the new creations are licensed under the identical terms.

For reprints contact: reprints@medknow.com nodule 4 years back. There was no other past medical history. Contrast-enhanced computerized tomography outside showed a large mass lesion involving the entire length of the cervix with the right parametrial extension. The exophytic mass measured $5.7 \mathrm{~cm} \times 5.5 \mathrm{~cm}$. There was no pelvic or para-aortic lymphadenopathy. She was staged cT2bcN0 and was given concurrent radiotherapy and platinum-based chemotherapy for 5 weeks. Posttherapy speculum examination revealed gross residual tumor in the cervix.

Posttherapy CT scan revealed a large residual proliferative mass in the anterior lip of the cervix, which was hyperintense on $\mathrm{T} 2$ and showed minimal enhancement postcontrast [Figure 1]. The mass measured $4 \mathrm{~cm} \times 3.5 \mathrm{~cm} \times 2.5 \mathrm{~cm}$ seen projecting into the vaginal cavity. There was no free fluid in the pelvis. Wertheim's hysterectomy was performed with nodal sampling. The specimen showed an exophytic firm tumor of $3.8 \mathrm{~cm} \times 3.2 \mathrm{~cm} \times 3.2 \mathrm{~cm}$ in the anterior lip of the cervix. Rest of the uterus and ovaries were grossly normal.

Histology showed a tumor with two different looking areas, merging with each other [Figure 2]. The tumor cells were small, arranged in nests and cords, with

How to cite this article: Muthusamy RK, Mehta SS.
Undifferentiated carcinoma of the uterine cervix
with evidence of its origin from small-cell
neuroendocrine carcinoma. Indian J Med Paediatr
Oncol 2018;39:536-8.

\section{Rajeshwari K Muthusamy, Sangita S Mehta}

Department of Pathology, Kovai Medical Center and Hospital, Coimbatore, Tamil Nadu, India

Address for correspondence: Dr. Rajeshwari K Muthusamy, Department of Pathology, Kovai Medical Center and Hospital, Coimbatore - 641 014, Tamil Nadu, India.

E-mail:drrajipranav@gmail. com

\section{Access this article online}

Website: www.ijmpo.org

DOI: 10.4103/ijmpo.ijmpo_23_17 Quick Response Code:

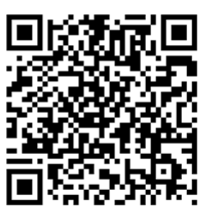


round nuclei and granular chromatin. Apoptotic bodies and increased mitosis were present [Figure 3a]. Merging with these tumor cells were large cells in islands and sheets, with moderate cytoplasm, enlarged nuclei, and prominent eosinophilic nucleoli [Figure 3b]. Bizarre nuclei, multinucleation, intranuclear cytoplasmic pseudoinclusions, lymphovascular invasion, and perineural invasion were seen. The smaller and larger tumor cells were immunoreactive to synaptophysin [Figure 4a] and CD56 [Figure 4b] with proliferation index of $14 \%$. Chromogranin, neuron-specific enolase (NSE), p16, and p63 were negative. With the above histomorphology and immunohistochemistry findings, a diagnosis of undifferentiated carcinoma of the uterine cervix with transition from high-grade SCNEC was made. There were no ascertainable therapy associated changes. She was on adjuvant chemotherapy with cisplatin.

\section{Discussion}

Neuroendocrine tumors of the cervix is defined by a consensus workshop in 1997 as carcinoid, atypical carcinoid, SCNEC, and large-cell NEC. ${ }^{[1]}$ NECs are uncommon, aggressive tumors of the cervix, with no defined precursor lesions and may coexist with glandular or squamous carcinoma. They constitute $<5 \%$ of the cervical malignancies, of which the predominant type being SCNEC. ${ }^{[2]}$ NEC is associated with high-risk human papillomavirus (HPV-18). ${ }^{[3]}$ High-grade NEC is highly aggressive, regardless of the morphological subtype or stage of the disease, with poorer survival in higher stage disease. ${ }^{[4]}$

Undifferentiated carcinoma of the uterine cervix is extremely rare, composed of sheets of cells with
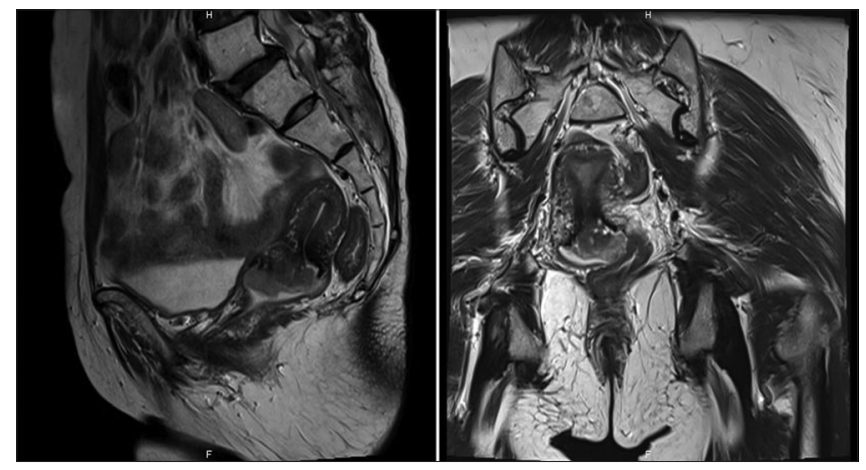

Figure 1: Posttherapy computed tomography images showing large residual tumor in the anterior lip of cervix

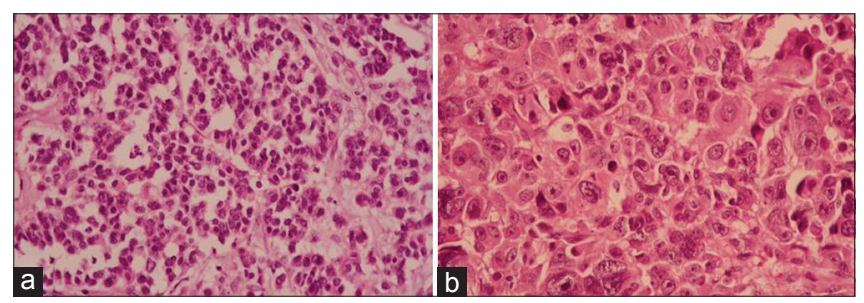

Figure 3: (a) Neuroendocrine carcinoma component showing small cells in nests and cords with granular chromatin. (b) Undifferentiated carcinoma areas with large nuclei and prominent nucleoli $(H$ and $E, \times 100)$ no histologic evidence of squamous or glandular differentiation. ${ }^{[5]}$ Immunohistochemistry with p63 or neuroendocrine markers helps in delineating the tumor type as squamous cell carcinoma or NEC. p16 and detection of HPV by in situ hybridization help in differentiating metastatic from primary tumors. ${ }^{[5]}$

Clinically, the tumor presents as like other cervical carcinomas as vaginal bleeding (as seen in the patient) and/or mass. ${ }^{[4,5]}$ The patient rarely may present with carcinoid symptoms due to metastatic disease. Histology of SCNEC is characterized by sheets of small cells with hyperchromatic nuclei, high nucleus-to-cytoplasmic ratio, and scant cytoplasm. Necrosis, abundant mitosis, apoptotic activity, and nuclear molding are characteristics. NEC of large cell type (LCNEC) has organoid or trabecular growth pattern with cells showing abundant cytoplasm and large nuclei with prominent nucleoli. ${ }^{[2,4]}$

Diagnosis of NEC is supported by staining of the tumor cells for neuroendocrine markers such as synaptophysin, chromogranin, NSE, and CD56. Synaptophysin and CD56 seem to be sensitive than chromogranin..$^{[2,4]}$ The tumor cells mostly show thyroid transcription factor-1 positivity, hence does not help in differentiating from SCNEC of the lung. They are variably negative to p63, useful in differentiating from small-cell nonkeratinizing squamous cell carcinoma. ${ }^{[4]}$

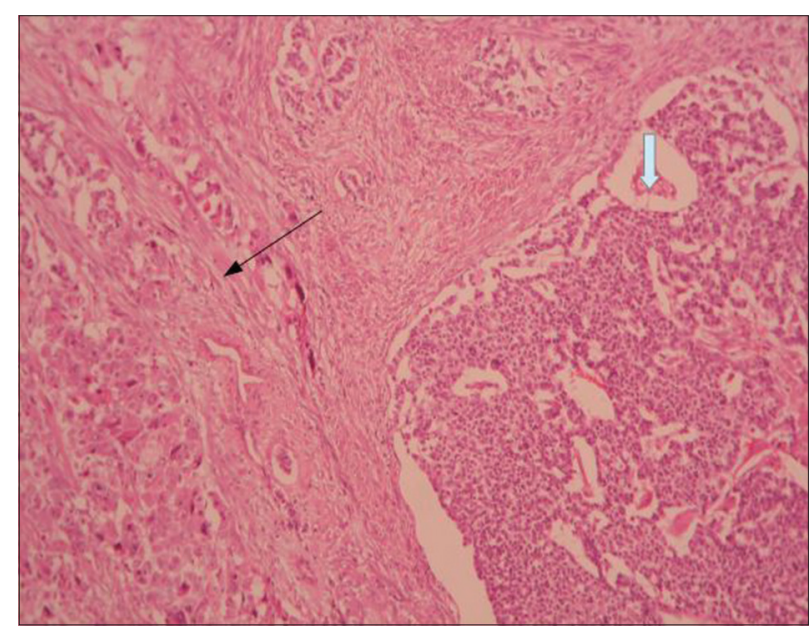

Figure 2: Undifferentiated carcinoma showing islands of large cells (black arrow) merging with small-cell neuroendocrine carcinoma in nests (block arrow) (H and E, ×40)

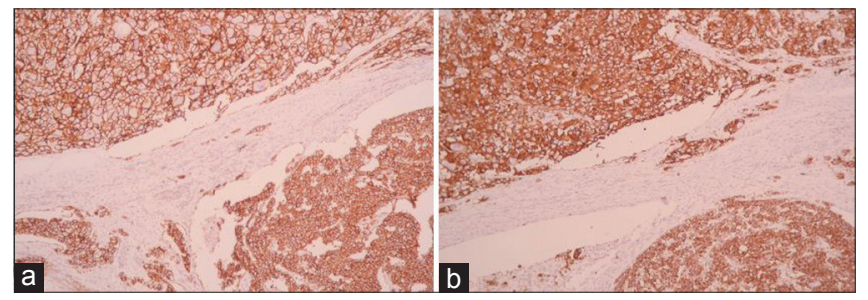

Figure 4: Undifferentiated carcinoma component in the upper left and neuroendocrine carcinoma component in the lower right showing positivity to synaptophysin (a) and CD56 (b) (×40) 
As SCNEC metastasize in the early stages of the disease, pelvic control by radical hysterectomy alone does not appear to be beneficial and needs adjuvant chemotherapy to control hematogenous spread, and thereby to improve the survival. ${ }^{[6]}$ The role of radiotherapy in control of local recurrence is debated. ${ }^{[6,7]}$ Previous studies have reported dismal prognosis despite various treatment modalities. Lee et al. have found that patients who received neoadjuvant chemotherapy (NACT) showed poorer prognosis than those who did not receive NACT. ${ }^{[6]}$ This case did not have any therapy-associated changes in histology, though there was a slight reduction in size by $2 \mathrm{~cm}$ in imaging. Federation of Gynecology and Obstetrics stage is an independent prognostic factor for NEC. ${ }^{[6]}$ The other probable prognostic factors discussed by previous studies include tumor size, presence and number of lymph node metastasis, stage, pure small-cell histology, parametrial involvement, deep stromal invasion, and smoking. ${ }^{[8-10]}$

To conclude, NECs are highly aggressive uncommon tumors, usually presenting at advanced stage of the disease and poorer survival even with multimodal therapy. Undifferentiated carcinoma of the cervix is extremely rare, with evidence of origin from SCNEC (with positivity for neuroendocrine markers as seen in our case), or from squamous or adenocarcinoma. Undifferentiated carcinoma is expected to behave aggressively as it gets dedifferentiated from a differentiated malignancy. Considering the extreme rarity of undifferentiated carcinoma and NEC of the uterine cervix, further case studies and follow-up of these might help in ascertaining the behavior of this tumor and to plan appropriate therapy.

\section{Financial support and sponsorship}

Nil.

\section{Conflicts of interest}

There are no conflicts of interest.

\section{References}

1. Gardner GJ, Reidy-Lagunes D, Gehrig PA. Neuroendocrine tumors of the gynecologic tract: A Society of Gynecologic Oncology (SGO) clinical document. Gynecol Oncol 2011;122:190-8.

2. Nucci MR, Lee KR, Crum CP. Tumors of the female genital tract, part E cervix. In: Fletcher CD, editor. Diagnostic Histopathology of Tumors. $4^{\text {th }}$ ed., Vol. 1. Philadelphia: Elsevier Saunders; 2013. p. 829-30.

3. Stoler MH, Mills SE, Gersell DJ, Walker AN. Small-cell neuroendocrine carcinoma of the cervix. A human papillomavirus type 18-associated cancer. Am J Surg Pathol 1991;15:28-32.

4. Colgan TJ, Kim I, Hirschowitz L, McCluggage WG. Neuroendocrine tumours. In: Kurman RJ, Carcangiu ML, Herrington CS, Young RH, editors. WHO Classification of Tumours of Female Reproductive Organs. $4^{\text {th }}$ ed. Lyon: IARC; 2014. p. 196-8.

5. Colgan TJ, Kim KR, Hirschowitz L, McCluggage WG. Other epithelial tumours. In: Kurman RJ, Carcangiu ML, Herrington CS, Young RH, editors. WHO Classification of Tumours of Female Reproductive Organs. $4^{\text {th }}$ ed. Lyon: IARC; 2014. p. 194-6.

6. Lee JM, Lee KB, Nam JH, Ryu SY, Bae DS, Park JT, et al. Prognostic factors in FIGO stage IB-IIA small cell neuroendocrine carcinoma of the uterine cervix treated surgically: Results of a multi-center retrospective Korean study. Ann Oncol 2008;19:321-6.

7. Bifulco G, Mandato VD, Giampaolino P, Piccoli R, Insabato L, De Rosa N, et al. Small cell neuroendocrine cervical carcinoma with 1-year follow-up: Case report and review. Anticancer Res 2009;29:477-84.

8. Wang KL, Yang YC, Wang TY, Chen JR, Chen TC, Chen HS, et al. Neuroendocrine carcinoma of the uterine cervix: A clinicopathologic retrospective study of 31 cases with prognostic implications. J Chemother 2006;18:209-16.

9. Viswanathan AN, Deavers MT, Jhingran A, Ramirez PT, Levenback C, Eifel PJ, et al. Small cell neuroendocrine carcinoma of the cervix: Outcome and patterns of recurrence. Gynecol Oncol 2004;93:27-33.

10. Chan JK, Loizzi V, Burger RA, Rutgers J, Monk BJ. Prognostic factors in neuroendocrine small cell cervical carcinoma: A multivariate analysis. Cancer 2003;97:568-74. 